\title{
Intravenous Methylprednisolone Versus Oral Prednisolone for West Syndrome: A Randomized Open-Label Trial
}

\author{
Dipti Kapoor ${ }^{1} \cdot$ Suvasini Sharma ${ }^{1}$ (D) Divyani Garg $^{2} \cdot$ Sukla Samaddar $^{1} \cdot$ Isha Panda ${ }^{1} \cdot$ Bijoy Patra $^{1} \cdot$ \\ Sharmila B Mukherjee ${ }^{1} \cdot$ Harish K. Pemde ${ }^{1}$
}

Received: 13 August 2020 / Accepted: 16 December 2020 / Published online: 11 February 2021

(C) Dr. K C Chaudhuri Foundation 2020

\begin{abstract}
Objective To compare intravenous methylprednisolone (IVMP) with oral prednisolone (OP) for the treatment of West syndrome. Methods In this randomized, open-label trial, children aged 2 to 30 mo presenting with epileptic spasms with hypsarrhythmia or its variants on EEG were randomized to receive either IVMP $(30 \mathrm{mg} / \mathrm{kg} / \mathrm{d}$ for $3 \mathrm{~d}$ followed by oral prednisolone taper) or OP ( $4 \mathrm{mg} / \mathrm{kg} / \mathrm{d}$ for two weeks followed by taper). The primary outcome measure was spasms cessation on day 14 . Secondary outcomes included time to response, electroclinical remission at 2 and $6 \mathrm{wk}$, and frequency of adverse effects. (ClinicalTrials. gov Identifier: NCT 03876444).

Results Sixty children were enrolled; 31 in the IVMP and 29 in the OP arm. Proportion of children achieving spasms cessation at day 14 was similar in both groups $(54.8 \%$ versus $68.9 \%, p=0.26)$. Time to achieve remission was lower in the IVMP group (mean $5.4 \pm 0.9$ versus $9.5 \pm 2.6 \mathrm{~d}, p<0.0001)$. Electroclinical remission at $2 \mathrm{wk}$ was similar in both groups $(51.6 \%$ versus $44.8 \%, p=0.59)$ but lower at $6 \mathrm{wk}$ in the IVMP group (45.2\% versus $75.9 \%, p<0.015)$. Adverse effects like sleep disturbance, irritability and hypertension were more common in IVMP group whereas weight gain was more common in the OP group.

Conclusions There was no significant difference in spasms cessation between the groups on day 14 although remission was higher at $6 \mathrm{wk}$ in OP group. Our study suggests that OP was better than IVMP in efficacy and sustained remission with fewer adverse effects.
\end{abstract}

Keywords Epileptic spasms · Infantile spasms $\cdot$ Hypsarrhythmia $\cdot$ ACTH $\cdot$ Hormonal therapy

\section{Introduction}

West syndrome (WS) is an age-related epileptic encephalopathy characterized by epileptic spasms, hypsarrhythmia on electroencephalography (EEG) and frequent neurodevelopmental delay/regression. Unfortunately, the treatment of this disorder remains challenging. Hormonal treatment i.e., adrenocorticotrophic hormone (ACTH) or oral prednisolone (OP) is the treatment of choice except in children with tuberous sclerosis (TSC) where vigabatrin is the drug of choice $[1,2]$. Steroids have been

Suvasini Sharma

sharma.suvasini@gmail.com

1 Division of Neurology, Department of Pediatrics, Kalawati Saran Children's Hospital and Lady Hardinge Medical College, New Delhi 110001, India

2 Department of Neurology, Smt. Sucheta Kriplani Hospital and Lady Hardinge Medical College, New Delhi, India used in various doses starting from $2 \mathrm{mg} / \mathrm{kg} / \mathrm{d}$ to up to $8 \mathrm{mg} / \mathrm{kg} /$ $\mathrm{d}$ [3]. Some studies have also used a fixed dose of $40-60 \mathrm{mg} / \mathrm{d}$ for $14 \mathrm{~d}[4]$.

Limitations including high cost and pain associated with intramuscular injections preclude the use of ACTH in children from low-resource settings. OP has disadvantages of requirements for steroid therapy over 4 to $6 \mathrm{wk}$ and frequent association with side effects such as irritability. Additionally, in the present settings, efficacy of OP is approximately $40 \%-50 \%$, presumably due to late presentation and predominantly symptomatic etiology [3].

Recently, there have been a few case series demonstrating the benefit of intravenous high dose methylprednisolone in children with infantile spasms (IS) [5-7]. Reported efficacy is around $60 \%-83 \%$, with spasms freedom being achieved very early (day 2-3 of treatment) among responders. Although this therapy necessitates hospitalization for $3 \mathrm{~d}$, overall treatment duration is shorter, and side effects such as irritability seem to be lesser with improved efficacy rate. 
Several studies have shown hormonal therapy to be superior to vigabatrin in WS, other than TSC. In the UKISS trial, hormonal treatments (prednisolone or tetracosactide depot) were associated with cessation of spasms in a higher proportion of infants, and with superior developmental scores in those infants who had no identified etiology for their spasms, than in those infants treated with vigabatrin $[8,9]$.

Therefore, the authors planned this randomized open-label trial to compare the efficacy of intravenous methylprednisolone (IVMP) with oral steroids taper versus OP in the treatment of IS.

\section{Material and Methods}

This open-label parallel group randomized controlled trial was undertaken between April 2019 and May 2020 at a pediatric tertiary hospital in northern India which conducts subspeciality clinics for children with epilepsy. The authors had initially planned the trial for $2 \mathrm{y}$. However, in view of the countrywide lockdown due to the COVID-19 pandemic, the authors had to prematurely terminate it. Hence, no new enrollments were undertaken after March 2020. Written informed consent was obtained from parents. Ethics approval was obtained from the institutional ethics committee. The study was registered with clinicaltrials.gov (NCT 03876444).

Children aged 2-30 mo with newly diagnosed epileptic spasms in clusters with electroencephalographic evidence of hypsarrhythmia or its variants were enrolled. These children were not on any antiseizure medications prior to enrolment. The authors did not include children with single spasms alone. The diagnosis was confirmed by two pediatric neurologists (DK, SS) based on clinical and electrographic features. Children with progressive neurological illness, renal, pulmonary, cardiac or hepatic dysfunction and/or severe malnutrition (weight for length and height less than $3 \mathrm{SD}$ for mean as per WHO growth charts) were excluded.

Consecutive children meeting the eligibility criteria were enrolled. Detailed history and examination were conducted according to a preset proforma. Results of neuroimaging and metabolic testing were documented. A baseline EEG (videoEEG whenever possible) was performed at enrolment for a minimum of $1 \mathrm{~h}$ including at least one sleep-wake cycle.

Eligible children were randomised using variable size, block randomization $(2,4$, or 6$)$ using computer-generated randomization sequence. Allocation concealment was done using sequentially-numbered, opaque, sealed envelopes. Neither the treating physicians nor the parents were blinded to group allocation. A chest radiograph and tuberculin test were obtained to screen for tuberculosis prior to starting hormonal therapy. Baseline weight and blood pressure (BP) were measured.
Enrolled children were randomized into two arms: IVMP arm received 3-d IVMP followed by short course oral steroids and the other arm received conventional OP (Table 1). Children in the IVMP arm were admitted for the first $3 \mathrm{~d}$ to receive intravenous steroids and then discharged with oral prednisolone taper over $2 \mathrm{wk}$. Oral steroids were administered in crushed form. During the in-patient stay, BP and blood sugar levels were monitored twice daily and serum electrolytes once daily. The OP arm was treated on out-patient basis. Parents were trained to document spasms and maintain seizure diaries.

Children were reviewed on out-patient basis via clinic visits once weekly for the first two weeks, followed by once in $2 \mathrm{wk}$ during the trial period of $6 \mathrm{wk}$. Spasms frequency as per parental seizure diaries was noted. Percentage reduction in seizure frequency compared to the baseline was assessed in accordance with seizure frequencies recorded daily by parents in the seizure diary. The proportion of patients who achieved spasms freedom according to parental reports was noted. A 1-h EEG record (video EEG whenever possible) including at least one sleep-wake cycle was repeated at 2 and $6 \mathrm{wk}( \pm 2 \mathrm{~d})$ to ascertain resolution of hypsarrhythmia. Electroclinical resolution was documented if the child was spasms-free with EEG resolution of hypsarrhythmia.

During each visit, the authors recorded: BP, body weight, blood and urinary glucose levels, irritability, sleep disturbances, increased appetite, gastrointestinal problems or infections. Hypertension was defined as blood pressure $\geq 95$ th percentile for the age and sex, when measured in a calm child with appropriate sized cuff. Any other parental concerns regarding side effects were also noted. Adverse effects in both groups was recorded. Oral prednisolone was dispensed from the hospital and compliance was determined by pill count. All responses were assessed by pediatric neurologists (DK, SS) unblinded to the allocation.

The primary outcome measure was to compare the efficacy of IVMP with OP in cessation of spasms (both clusters and individual spasms), defined as no witnessed spasms for at least $48 \mathrm{~h}$ on day 14 from trial entry, as per parental reports. The secondary outcomes were (a) time to response (defined as the first day after initiation of trial treatment on which spasms were not seen) (b) electroclinical response at $2 \mathrm{wk}$ and at 6 wk; i.e., sustained spasms cessation with repeat EEG at $6 \mathrm{wk}$ showing no recurrence of hypsarrhythmia. The outcome measure of sustained electroclinical resolution at $6 \mathrm{wk}$ was chosen as per the Infantile Spasms Delphi consensus 2004 [10] and (c) to compare the safety of IVMP followed by oral prednisolone with HDOP in terms of nature and proportion of adverse effects among newly diagnosed patients with IS.

This trial was planned to test the hypothesis that administration of IVMP may be more efficacious than OP. By use of a null hypothesis that the two groups would not have a significant difference in spasms control outcome, and by defining 
Table 1 Dosage schedule in the IV methylprednisolone and the oral prednisolone group
Group 1: Intravenous methylprednisolone

Group 2: Oral prednisolone

Day 1-3: Intravenous methylprednisolone $30 \mathrm{mg} / \mathrm{kg} / \mathrm{d}$

Day 4-7: Oral prednisolone $2 \mathrm{mg} / \mathrm{kg} / \mathrm{d}$

Day 8-14: Oral prednisolone $1 \mathrm{mg} / \mathrm{kg} / \mathrm{d}$
Day 1-14 (2 wk): $4 \mathrm{mg} / \mathrm{kg} / \mathrm{d}$

Day 15-21 (1 wk): $2 \mathrm{mg} / \mathrm{kg} / \mathrm{d}$

Day 22-28 (1 wk): $1 \mathrm{mg} / \mathrm{kg} / \mathrm{d}$
$25 \%$ as minimum outcome difference of clinical importance, the authors estimated that a sample size of 56 patients per group (1:1 allocation ratio) would enable the detection of difference that will be significant at $5 \%$ with a power of $80 \%$. This calculation was based on an expected responder rate of $40 \%$ in the OP arm based on past experience at the authors' center [11].

Data were recorded on a predesigned proforma and managed on an Excel spreadsheet. Quantitative variables were summarised as mean \pm SD or median (minimum, maximum) as appropriate. Categorical variables were summarised as frequency. Chi square test and Fisher exact tests were used to compare categorical data. Mann-Whitney test was used for quantitative data with continuous variables. A $p$ value $<0.05$ was considered statistically significant. All statistical tests were done using Stata 14.0 software. Analysis was intention-to-treat.

\section{Results}

A total of 60 children were randomized: 31 children to the IVMP group and 29 to the OP group during the study period (Fig. 1). Baseline demographic and clinical characteristics of the two groups were comparable (Table 2). The median lag (from age of onset of spasms to presentation) was 6.4 mo (SD $3.8 \mathrm{mo}$ ) in the IVMP and $7.2 \mathrm{mo}$ (SD $4.7 \mathrm{mo}$ ) in the OP group $(p=0.46)$. Etiology was known in $51(85 \%)$ patients in both groups with the most common being symptomatic neonatal hypoglycemia; all these children had associated MRI changes of gliosis with/without encephalomalacia in the occipital and/ or parietal lobe. In 9 patients, no etiology could be ascertained. All children enrolled had developmental delay.

There was no statistical difference in the proportion of children achieving spasms cessation at day 14 in IVMP versus the OP group (17/31 [54.8\%] versus 20/29 [68.9\%], $p=0.26$ ) (Table 3). However, time to achieve remission was less in the IVMP group (mean $5.4 \pm 0.9$ versus $9.5 \pm 2.6 \mathrm{~d}$, $p<0.0001$ ). There was no significant difference in proportion of children achieving electroclinical resolution at $2 \mathrm{wk}$.

Six children (19.4\%) in the IVMP group had recurrence of spasms within $6 \mathrm{wk}$ of initiating treatment after initial remission, with median time to recurrence being $38.7 \mathrm{~d}$ (IQR 35-42 d) (Table 3). However, none of the patients in the OP group had recurrence of spasms in the follow-up duration. The proportion of children with electroclinical remission at $6 \mathrm{wk}$ was significantly lower in the IVMP versus the OP group ( $45.2 \%$ versus $75.9 \%, p<0.015)$.

Adverse effects observed in both groups included increased appetite, weight gain, sleep disturbances, excessive irritability, hypertension, gastrointestinal complications (vomiting, gastritis and abdominal pain), glycosuria, and infections (Table 4). However, increased appetite (65.5\% vs 3.2\%) and weight gain $(75.9 \%$ vs $16.1 \%)$ were more common in the OP group $(p<0.05)$; whereas, sleep disturbances $(61.3 \%$ vs $20.7 \%$, $p=0.0014)$, excessive irritability $(74.2 \%$ vs $31 \%, p=$ 0.0008 ) and hypertension ( $35.5 \%$ vs $10.3 \%, p=0.032$ ) were more frequently seen in the IVMP group. All children with hypertension required brief course of oral antihypertensive amlodipine and BP readings normalised within 2-4 wk time, followed by tapering and withdrawal of drug. None of the children were symptomatic for hypertension. One child in the IVMP group developed asymptomatic hyponatremia which resolved spontaneously within $42 \mathrm{~h}$.

\section{Discussion}

The clinical characteristics of this cohort of children with WS including male preponderance, late age of presentation, longer lead time and predominant aetiology of perinatal brain injury is reminiscent of the center's past experience with WS [3, 11-13]. The major proportion of the etiology was contributed by neonatal hypoglycemic brain injury and perinatal asphyxia. Neonatal hypoglycemic brain injury is being increasingly recognized as a cause of WS in low-resource settings [14]. The significant delay between clinical onset of spasms and initiation of treatment (lead time) could be attributed to suboptimal follow up of high-risk infants and lack of awareness regarding early recognition of IS, both amongst parents as well as primary care physicians [13].

To the best of authors' knowledge, this is the first study comparing IVMP to OP for the treatment of WS. Over the past two decades, high-dose IVMP pulse therapy has been used in various epilepsies in order to reduce the side effects of prolonged oral steroid therapy, while maintaining efficacy [15-18]. Administered according to different regimens (with dosages ranging from $15 \mathrm{mg} / \mathrm{kg} / \mathrm{d}$ for three or five days to $30 \mathrm{mg} / \mathrm{kg} / \mathrm{d}$ for two or three days) repeated at different intervals (weekly or monthly), it has been shown to be successful 
Table 2 Baseline characteristics of the study population

\begin{tabular}{|c|c|c|c|}
\hline Baseline characteristics & $\begin{array}{l}\text { Intravenous methylprednisolone } \\
\text { (IVMP) group } \\
(n=31)\end{array}$ & $\begin{array}{l}\text { Oral prednisolone } \\
(\mathrm{OP}) \text { group } \\
(n=29)\end{array}$ & $\begin{array}{l}P \\
\text { value }\end{array}$ \\
\hline \multicolumn{4}{|l|}{ Sex } \\
\hline $\begin{array}{l}\text { Male n }(\%) \\
\text { Female n }(\%)\end{array}$ & $\begin{array}{r}22(71) \\
9(29)\end{array}$ & $\begin{array}{l}19(65.5) \\
10(34.5)\end{array}$ & 0.65 \\
\hline \multicolumn{4}{|l|}{ Age at onset (mo) } \\
\hline Median (Interquartile range) & $5(3-7)$ & $5(3-8)$ & 0.58 \\
\hline \multicolumn{4}{|l|}{ Age at presentation (mo) } \\
\hline Median (Interquartile range) & $11(9-13)$ & $12(7.5-18)$ & 0.93 \\
\hline \multicolumn{4}{|l|}{ Lead time to treatment (mo) } \\
\hline Median (Interquartile range) & $6(4-8)$ & $7(3-11.5)$ & 0.46 \\
\hline \multicolumn{4}{|l|}{ Etiology n (\%) } \\
\hline \multicolumn{4}{|l|}{ Known } \\
\hline Neonatal hypoglycemia & $13(41.9)$ & $10(34.4)$ & 0.55 \\
\hline Perinatal asphyxia & $10(32.2)$ & $11(37.9)$ & 0.64 \\
\hline Neonatal sepsis & $2(0.06)$ & 0 & 0.49 \\
\hline Cerebral malformations & $1(0.03)$ & 0 & 1.00 \\
\hline Post-encephalitic sequelae & $2(0.06)$ & $2(0.07)$ & 0.94 \\
\hline Unknown & $3(0.1)$ & $6(0.2)$ & 0.23 \\
\hline \multicolumn{4}{|l|}{ EEG at presentation n $(\%)$} \\
\hline $\begin{array}{l}\text { Hypsarrythmia } \\
\text { Hypsarrythmia variant }\end{array}$ & $\begin{array}{l}18(58.1) \\
13(41.9)\end{array}$ & $\begin{array}{l}14(48.3) \\
15(51.7)\end{array}$ & 0.45 \\
\hline \multicolumn{4}{|l|}{ Comorbidities n (\%) } \\
\hline Microcephaly & $20(64.5)$ & $21(72.4)$ & 0.51 \\
\hline Cerebral palsy & $20(64.5)$ & $22(75.9)$ & 0.34 \\
\hline $\begin{array}{l}\text { Vision abnormality (refractive } \\
\text { error/squint) }\end{array}$ & $13(41.9)$ & $10(34.5)$ & 0.56 \\
\hline Hearing deficit & $9(29.0)$ & $11(37.9)$ & 0.47 \\
\hline
\end{tabular}

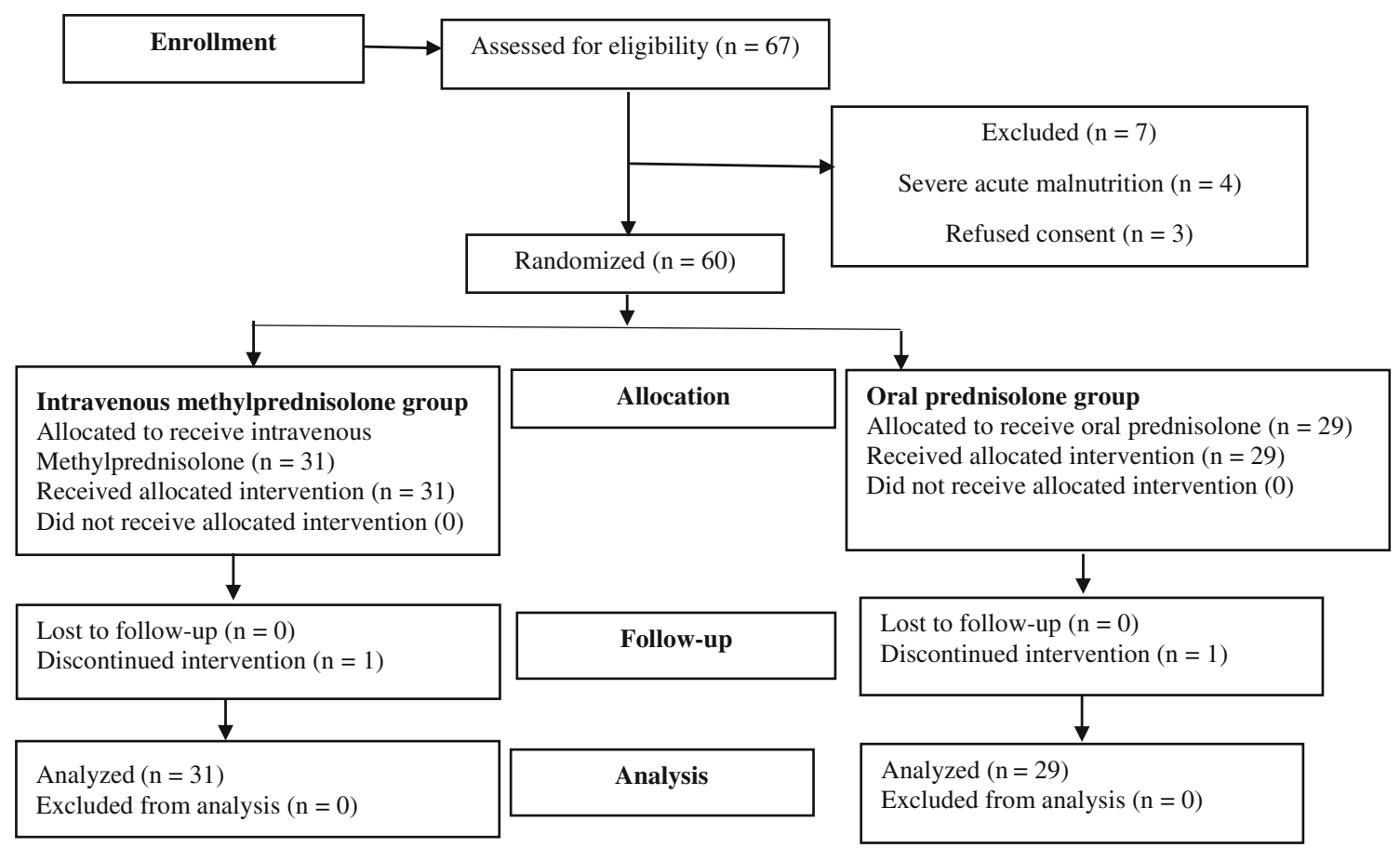

Fig. 1 Flow of patients in the study 
Table 3 Treatment efficacy of intravenous methylprednisolone (IVMP) versus oral prednisolone (OP)

\begin{tabular}{|c|c|c|c|c|}
\hline & $\begin{array}{l}\text { IVMP group } \\
(\mathrm{n}=31)\end{array}$ & $\begin{array}{l}\text { OP group } \\
(\mathrm{n}=29)\end{array}$ & $\begin{array}{l}\text { Odds ratio } \\
\text { ( } 95 \% \text { Confidence Interval) }\end{array}$ & $P$ value \\
\hline $\begin{array}{l}\text { Number of patients achieving spasm remission } \\
\text { as per parental reports at Day } 14\end{array}$ & $17(54.8 \%)$ & $20(68.9 \%)$ & $1.3(0.6-2.9)$ & 0.26 \\
\hline \multicolumn{5}{|l|}{ Days to achieve spasm cessation } \\
\hline Mean (SD) & $5.4 \pm 0.9$ & $9.5 \pm 2.6$ & - & $<0.00001$ \\
\hline $\begin{array}{l}\text { Proportion of children with electroclinical } \\
\text { resolution at } 2 \mathrm{wk}\end{array}$ & $16(51.6 \%)$ & $13(44.8 \%)$ & $0.9(0.4-2.1)$ & 0.59 \\
\hline $\begin{array}{l}\text { Proportion of children with electroclinical } \\
\text { resolution at } 6 \mathrm{wk}\end{array}$ & $14(45.2 \%)$ & $22(75.9 \%)$ & $1.7(0.7-3.9)$ & 0.015 \\
\hline Recurrence of spasms within $6 \mathrm{wk}$ & $6(19.4)$ & 0 & $0.08(0.004-1.5)$ & 0.0242 \\
\hline
\end{tabular}

in different epilepsies such as Landau-Kleffner syndrome, absence seizures, and epileptic encephalopathies) [5-7, 16]. However, whether the differences in pharmacodynamics, pharmacokinetics or mechanism of action between methylprednisolone and prednisolone can lead to differences in their efficacy in various epileptic syndromes is not known.

In the present study, the IVMP group received the 3-d IVMP pulse followed by short and rapidly tapering course of oral prednisolone for a total duration of $2 \mathrm{wk}$. With this, the day 14 outcome in terms of clinical and electroclinical resolution was similar to OP with added advantage of reduced time to achieve remission. The short-term outcome findings are similar those described in previous case series. Hassanzadeh et al. in their study on efficacy of intravenous IVMP in a cohort of 20 children observed mean rapid remission of $4.41 \pm 1.50 \mathrm{~d}$ with clinical remission in $60 \%$ and resolution of hypsarrythmia on follow-up EEG at 2 wk in $65 \%$ of patients [5]. Mytinger et al. reported their experience with use of IVMP pulse followed by 8 -wk course of oral steroids in 10 participants with IS. Remission was achieved in 5/10 infants (50\%) between 2 to 6 $\mathrm{d}$ after onset of treatment and resolution of hypsarrythmia

Table 4 Adverse effects in the intravenous methylprednisolone (IVMP) versus oral prednisolone $(\mathrm{OP})$ group

\begin{tabular}{lllc}
\hline & $\begin{array}{l}\text { IVMP group } \\
(\mathrm{n}=31)\end{array}$ & $\begin{array}{l}\text { OP group } \\
(\mathrm{n}=29)\end{array}$ & $p$ value \\
\hline Sleep disturbances & $19(61.3 \%)$ & $6(20.7 \%)$ & 0.0014 \\
Irritability & $23(74.2 \%)$ & $9(31 \%)$ & 0.0008 \\
GI complications & $3(9.7 \%)$ & $3(10.3 \%)$ & 0.93 \\
Increased appetite & $1(3.2 \%)$ & $19(65.5 \%)$ & $<0.0001$ \\
Weight gain & $5(16.1 \%)$ & $22(75.9 \%)$ & $<0.0001$ \\
Hypertension & $11(35.5 \%)$ & $3(10.3 \%)$ & 0.032 \\
Infections & $2(6.5 \%)$ & 0 & 0.49 \\
Glycosuria & $3(9.7 \%)$ & $5(17.2 \%)$ & 0.47 \\
Dyselectrolytemia & $1(3.2 \%)$ & 0 & 0.48 \\
\hline
\end{tabular}

GI Gastrointestinal occurred in 50\% of the patients [6]. Yeh et al. used IVMP followed by short course of oral steroids and observed that in nine of 14 patients $(64.3 \%)$, rapid cessation of spasms occurred with mean time to cessation of $3.0 \mathrm{~d}$ [7].

One of the main drawbacks with the use of IVMP was early recurrence within $6 \mathrm{wk}$, seen in $6 / 17$ responders. Consequently, the proportion of children with electroclinical remission at $6 \mathrm{wk}$ was significantly lower in the IVMP as compared to the OP group. This observation demonstrates lack of prolonged action of IVMP on control of spasms. These findings are consistent with the observations made by Yeh et al. in their study, where $45 \%$ of the patients relapsed electroclinically after discontinuation of treatment [7]. One of the reasons for the worse $6 \mathrm{wk}$ response in the IVMP group may be that we used a short oral steroid taper in the IVMP group (total therapy duration of $2 \mathrm{wk}$ versus total therapy duration of $4 \mathrm{wk}$ in the OP group). Despite this, similar outcomes at two weeks and similar to other studies [6] does support this short course steroid taper in the IVMP arm in the short-term.

Monitoring for adverse effects revealed presence of significant number of patients developing sleep disturbances, irritability and hypertension in the IVMP group, all of which arose in the first 3-4 d of treatment, suggesting that these were related to the IVMP regimen. These findings contrast with previous studies where such side effects occurred in only a small percentage of patients [5, 7]. Hypertension was transient and could be controlled with amlodipine. The drug could be withdrawn after BP control during the follow-up. There were two episodes of infection in the IVMP group: one was a urinary tract infection and the other was pneumonia. The most common adverse effects in the OP group were increased appetite and weight gain, which are known reversible side effects of prolonged steroid therapy [19-21]. A pragmatic advantage of oral prednisolone in the present study's setting is that it is considerably less expensive and easily available compared to IVMP, which is a costly proposition for out-of-pocket 
expenditure. The IVMP regimen would cost a patient 10 times the OP regimen on average in the authors' setting. However, in a government setting such as the authors, IVMP is available free of cost to patients.

The present study had some limitations. It was unblinded and parental reporting of spasms may not have been accurate. Due to resource constraints, the authors could not perform 24-h EEG to substantiate parental reporting of complete spasms cessation. The lack of objective EEG scoring was another limitation. Additionally, the study did not address risk for relapse of spasms in the longer term; with the longer duration of treatment with OP, the relapse could be only delayed. It is possible that 3-6 mo later, the relapse rate could potentially be similar between the two treatments. However, despite these limitations, the authors observed that though administration of IVMP is associated with significantly more rapid electroclinical resolution of spasms, they could not demonstrate any prolonged effect over control of spasms as observed by early recurrence of spasms within $6 \mathrm{wk}$. The authors also observed significantly higher incidence of irritability, sleep disturbances and transient hypertension in the IVMP group.

\section{Conclusions}

The present study failed to demonstrate the superiority of IVMP at $2 \mathrm{wk}$, considering the limitations of the study. However, time to achieve cessation of spasms was significantly shorter than that with oral steroids at $4 \mathrm{mg} / \mathrm{kg} / \mathrm{d}$. However, long-term comparative profile in outcomes with IVMP compared to conventional steroid therapy needs further exploration.

Acknowledgements The authors thank their EEG technicians, Mr. Manas Guchait, Mr. Krishan Sagar and Mr. Kapil for help with EEGs and Mrs. Babita Tyagi for administrative assistance.

Authors' Contributions DK: Collected the data and drafted the paper. S Sh: Guided the study and is the guarantor for this paper. DG: Helped in data interpretation, analysis, literature review and writing. S Sa and IP: Helped in data collection and execution of the study. BP, SBM, HKP guided the study. S Sh will act as guarantor for this paper.

\section{Compliance with Ethical Standards}

The study was approved by the Institutional Ethics Committee.

Conflict of Interest None.

Consent to Participate Written informed consent to participate in the study was obtained from the patients' guardian.

\section{References}

1. Go CY, Mackay MT, Weiss SK, et al. Evidence-based guideline update: medical treatment of infantile spasms. Report of the guideline development Subcommittee of the American Academy of neurology and the practice Committee of the Child Neurology Society. Neurology. 2012;78:1974-80. https://doi.org/10.1212/WNL. 0b013e318259e2cf.

2. Wanigasinghe J, Arambepola C, Sri Ranganathan S, Sumanasena S, Attanapola G. Randomized, single-blind, parallel clinical trial on efficacy of oral prednisolone versus intramuscular corticotropin on immediate and continued spasm control in west syndrome. Pediatr Neurol. 2015;53:193-9. https://doi.org/10.1016/j.pediatrneurol. 2015.05.004.

3. Chellamuthu P, Sharma S, Jain P, Kaushik JS, Seth A, Aneja S. High dose $(4 \mathrm{mg} / \mathrm{kg} /$ day $)$ versus usual dose $(2 \mathrm{mg} / \mathrm{kg} /$ day $)$ oral prednisolone for treatment of infantile spasms: an open-label, randomized controlled trial. Epilepsy Res. 2014;108:1378-84. https:// doi.org/10.1016/j.eplepsyres.2014.06.019.

4. O'Callaghan FJK, Edwards SW, Alber FD, et al. Safety and effectiveness of hormonal treatment versus hormonal treatment with vigabatrin for infantile spasms (ICISS): a randomised, multicentre, open-label trial. Lancet Neurol. 2017;16:33-42. https://doi.org/10. 1016/S1474-4422(16)30294-0.

5. Hassanzadeh Rad A, Aminzadeh V. Infantile spasms treated with intravenous methypredinsolone pulse. Iran J Child Neurol. 2017;11:8-12.

6. Mytinger JR, Quigg M, Taft WC, Buck ML, Rust RS. Outcomes in treatment of infantile spasms with pulse methylprednisolone. J Child Neurol. 2010;25:948-53. https://doi.org/10.1177/ 0883073809356107.

7. Yeh H-R, Kim M-J, Ko T-S, Yum M-S, You S-J. Short-term outcome of intravenous methylprednisolone pulse therapy in patients with infantile spasms. Pediatr Neurol. 2017;71:50-5. https://doi. org/10.1016/j.pediatrneurol.2017.03.017.

8. Lux AL, Edwards SW, Hancock E, et al. The United Kingdom infantile spasms study comparing vigabatrin with prednisolone or tetracosactide at 14 days: a multicentre, randomised controlled trial. Lancet. 2004;364:1773-8. https://doi.org/10.1016/S0140-6736(04) 17400-X.

9. Lux AL, Edwards SW, Hancock E, et al. The United Kingdom infantile spasms study (UKISS) comparing hormone treatment with vigabatrin on developmental and epilepsy outcomes to age 14 months: a multicentre randomised trial. Lancet Neurol. 2005;4: 712-7. https://doi.org/10.1016/S1474-4422(05)70199-X.

10. Lux AL, Osborne JP. A proposal for case definitions and outcome measures in studies of infantile spasms and west syndrome: consensus statement of the West Delphi group. Epilepsia. 2004;45: 1416-28. https://doi.org/10.1111/j.0013-9580.2004.02404.x.

11. Kunnanayaka V, Jain P, Sharma S, Seth A, Aneja S. Addition of pyridoxine to prednisolone in the treatment of infantile spasms: a pilot, randomized controlled trial. Neurol India. 2018;66:385-90. https://doi.org/10.4103/0028-3886.227281.

12. Gupta J, Sharma S, Mukherjee SB, Jain P, Aneja S. Neurodevelopmental and epilepsy outcomes of children with west syndrome: a cross-sectional study from North India. Ann Indian Acad Neurol. 2020;23:177. https://doi.org/10.4103/aian.AIAN_503 18.

13. Kaushik JS, Patra B, Sharma S, Yadav D, Aneja S. Clinical spectrum and treatment outcome of west syndrome in children from northern India. Seizure. 2013;22:617-21. https://doi.org/10.1016/ j.seizure.2013.04.014

14. Kapoor D. Sidharth, Sharma S, Patra B, Mukherjee S, Pemde HK. Electroclinical spectrum of childhood epilepsy secondary to 
neonatal hypoglycemic brain injury in a low resource setting: a 10year experience. Seizure. 2020;79:90-4.

15. Dontin SD, Olivotto S, Teutonico F, Altieri N, Balottin U, Veggiotti P. Corticosteroid therapy for epileptic encephalopathies other than west syndrome. J Pediatr Epilepsy. 2013;02:97-107. https://doi.org/10.3233/PEP-13048.

16. Hancock E, Osborne JP, Milner P. The treatment of west syndrome: a cochrane review of the literature to december 2000. Brain Dev. 2001;23:624-34. https://doi.org/10.1016/s0387-7604(01)00299-6.

17. Heyman E, Lahat E, Gandelman-Marton R. Interictal encephalography can influence patient selection for methylprednisolone therapy in pediatric refractory epilepsy. J Child Neurol. 2012;27:162-7. https://doi.org/10.1177/0883073811414905.

18. Sevilla-Castillo RA, Palacios GC, Ramirez-Campos J, Mora-Puga M, Diaz-Bustos R. Methylprednisolone for the treatment of children with refractory epilepsy. Neuropediatrics. 2009;40:2658. https://doi.org/10.1055/s-0030-1249653.

19. Gupta R, Appleton R. Corticosteroids in the management of the paediatric epilepsies. Arch Dis Child. 2005;90:379-84. https://doi. org/10.1136/adc.2004.051375.

20. Hancock EC, Osborne JP, Edwards SW. Treatment of infantile spasms. Cochrane Database Syst Rev. 2013;6:CD001770. https:// doi.org/10.1002/14651858.CD001770.pub3.

21. Kossoff EH, Hartman AL, Rubenstein JE, Vining EPG. High-dose oral prednisolone for infantile spasms: an effective and less expensive alternative to ACTH. Epilepsy Behav EB. 2009;14:674-6. https://doi.org/10.1016/j.yebeh.2009.01.023.

Publisher's Note Springer Nature remains neutral with regard to jurisdictional claims in published maps and institutional affiliations. 